\title{
Drug safety of skin care products - neuro- and non-neuro- mediated actions
}

\author{
Pierre A. Guertin* \\ Department of Psychiatry and Neurosciences, Laval University Medical Center - CHU de Quebec, Canada
}

\begin{abstract}
The skin is the largest organ of the body. As any other organ, its constitutive structures and mechanisms, are controlled by signals arising from the central, peripheral and autonomous nervous systems. Most of its functions depend upon water content levels. Both the sudoriferous gland and the sebaceous gland are known to be key players in regulation of body temperature, sweating, protective functions and antibacterial activities - through non-neural- and neural system-mediated actions. Although skin care products are generally not bound to meet safety requirements similar to drugs (i.e., small molecule therapeutics or biologics) prior to approval and marketing, there complex effects upon central and peripheral mechanisms shall be considered as a significant reason for changing guidelines associated their development.
\end{abstract}

\section{Introduction}

The skin is the largest organ $\left(\sim 2 \mathrm{~m}^{2}\right)$ of our body and the first line of defense against external factors. The control of its water content level is pivotal in maintaining skin health and integrity. Dysfunctional skin moisture is in fact associated with several debilitating dry skin problems such as xerosis, atopic dermatitis, psoriasis, and rosacea.

In mammals, the skin is composed of four layers - epidermis, basement membrane, dermis and subcutaneous (hypodermis). The epidermis - stratum corneum (SC), granolosum (SG), spinosum, basal contains no blood vessel per se although the deepest layers are irrigated by diffusion from blood capillaries from the dermis. [1]. The latter harbors also mechanoreceptors, thermoreceptors and nociceptors for various senses. These receptors send directly or indirectly to the central nervous system, inputs involved in assessing hot/cold, pressure/touch, pain, vibration, or chemicals as well as vasocontraction, vasodilatation, body temperature regulation, barrier function, secretion, growth, differentiation, cell nutrition, nerve growth, inflammatory and immune responses, apoptosis, proliferation, and wound healing [1].

The inner milieu of our body consists of about $70 \%$ water (genderand age-based differences ranging from 55-75\%) - that is significantly less than ambient air in general (1\% water) [2]. Two main mechanisms affect water content at the cellular level - 1) water transport from inner layers towards the epidermis and, 2) water transport and evaporation from epidermal layers towards the external environment.

To increase water content levels, water transport from inner layers, including from blood vessels, seeks bringing in water towards the dermis and, hence, the epidermis. Once SC layer is reached, water is eventually being lost to evaporation. Consequently, to decrease water content losses, it is imperative to limit evaporation and sweating in some conditions. Aquaporin channels, supported by water-binding molecules such as glycerol, expressed on vascular endothelial cells, facilitate water exchange and transport between blood and dermis [3]. Blood volumes, circulating flow levels and regional distribution are directly affecting water transport levels [4]. Actions upon these systems critically depend upon a complex variety of neural mechanisms - i.e., hypothalamic-pituitary-adrenal axis (e.g., arteriovenous anastomoses) raphe nucleus, medulla oblongata, preoptic area, hypothalamus, pons and periaqueductal gray matter [5-9].

Sudoriferous glands, essentially the eccrine subtype, is the primary structure of the skin responsible for thermoregulating sweating in humans - it is found over the entire body surface [1] although areas with greater density enable superior thermoregulating capabilities [10]. Recordings postganglionic skin sympathetic nerve activity showed that a large fraction of the sympathetic activity during heat stress is essentially sudomotor in nature through acetylcholine release that binds to muscarinic receptors. Other neural systems are also apparently involved (e.g., $\alpha$ - or $\beta$-adrenergic, vasoactive intestinal polypeptide, calcitonin gene-related peptide) [11-13]. Sebum secretion from sebaceous glands is also pivotal to moist skin. It also possesses an innate antibacterial activity and has a pro- and anti-inflammatory function that may improve healing [14]. The human skin and its sebaceous glands express a plethora of neuropeptidergic receptors - e.g., corticotropin-releasing hormone, transient receptor potential vanilloid-1, melanocortins, $\beta$-endorphin, vasoactive intestinal polypeptide, neuropeptide $\mathrm{Y}$, substance $P$, and calcitonin gene-related peptide [14]. Dysregulation of substance $\mathrm{P}$ and vasointestinal peptide levels plays a role in the pathogenesis of acne vulgaris whereas, in response to stress, substance $\mathrm{P}$ can promote the development of cytoplasmic organelles in sebaceous cells, stimulate sebaceous germinative cells, and induce significant sebaceous gland activity [14-16].

In most countries, safety is the priority concern of regulatory agencies for drug development and approval. Both pre-clinical and

Correspondence to: Pierre A Guertin, Department of Psychiatry and Neurosciences, Laval University Medical Center - CHU de Quebec, Canada. E-mail: pierre.guertin@crchul.ulaval.ca

Received: November 17, 2016; Accepted: November 28, 2016; Published: December 02, 2016 
clinical data in animals and humans are required. Phase I and phase II clinical studies are particularly important since considered the first steps in assessing initial safety and dosing. Challenges associated with safety are so high that most drugs fail to be approved - only one new drug every 5,000 to 10,000 tested chemical compounds is generally approved [17]. In clear contrast, virtually all skin products are a priori approved. Although some exceptions exist (there is a list of banned substances that are permitted only in drug rather cosmetic products e.g., [18]), there is no significant regulation except for labeling and false claims that may prevent any skin care product to be commercialized in North America and Europe. David Suzuki has published a clear list of ingredients that should be banned based on compelling scientific evidence but that are still routinely used in the cosmetic industry worldwide [19]- e.g., BHA/BHT, coal tar dyes, DEA-related ingredients, dibutyl phthalate, formaldehyde-releasing preservatives, parabens, parfum (fragrance), PEG compounds, petrolatum, siloxanes, sodium laureth sulfate, triclosan. In fact, most of these unsafe ingredients are used in combination sometimes constituting between 1 and $50 \%$ of the final product $[20,21]$.

\section{Conclusion}

In conclusion, 1) Many new control mechanisms could become future targets for the development of innovative CNS and/or PNS products against various types of skin problems. 2) As of now, only a few science-based, innovative skin care products are available for temporary stimulation of lipid-rich epidermal layers and stimulation of endogenous water transport mechanisms [21,22]. 3) It is thus imperative for the industry to rapidly adopt heightened standards and severe regulations (as for drugs) if safety is to be considered a top priority in the development of next-generation skin products (antiaging, repair, and/or moisturizer) that will likely be acting upon both neuronal and non-neuronal target mechanisms for significant efficacy.

\section{References}

1. McGrath JA, Eady RA, Pope FM (2004) Rook's Textbook of Dermatology (7th ed.). Blackwell Publishing. pp. 3.1-3.6.

2. Iozzo RV (2005) Basement membrane proteoglycans: from cellar to ceiling. Nat Rev Mol Cell Biol 6: 646-656. [Crossref]

3. Beitz E. Aquaporins. Handbook of Experimental Pharmacology Springer, Berlin, 2004; pp. 210 .

4. Papp A, Romppanen E, Lahtinen T, Uusaro A, Härmä M, et al. (2005) Red blood cell and tissue water content in experimental thermal injury. Burns 31: 1003-1006. [Crossref]

5. Krogstad AL, Elam M, Karlsson T, Wallin BG (1995) Arteriovenous anastomoses and the thermoregulatory shift between cutaneous vasoconstrictor and vasodilator reflexes. J Auton Nerv Syst 53: 215-222. [Crossref]

6. Blessing WW, Yu YH, Nalivaiko E (1999) Raphe pallidus and parapyramidal neurons regulate ear pinna vascular conductance in the rabbit. Neurosci Lett 270: 33-36. [Crossref]

7. Key BJ, Wigfield CC (1994) The influence of the ventrolateral medulla on thermoregulatory circulations in the rat. J Auton Nerv Syst 48: 79-89. [Crossref]

8. Ootsuka Y, Terui N (1997) Functionally different neurons are organized topographically in the rostral ventrolateral medulla of rabbits. J Auton Nerv Syst 67: 67-78.

9. Owens NC1, Ootsuka Y, Kanosue K, McAllen RM (2002) Thermoregulatory control of sympathetic fibres supplying the rat's tail. $J$ Physiol 543: 849-858. [Crossref]

10. Shibasaki M, Wilson TE, Crandall CG (2006) Neural control and mechanisms of eccrine sweating during heat stress and exercise. J Appl Physiol 100: 1692-1701. [Crossref]

11. Takahashi N, Nakamura T, Kanno N, Kimura K, Toge Y, et al. (2011) Local heat application to the leg reduces muscle sympathetic nerve activity in human. Eur J Appl Physiol 111: 2203-2211. [Crossref]

12. Schmelz M, Schmidt R, Bickel A, Torebjork HE, Handwerker HO (1998) Innervation territories of single sympathetic C fibers in human skin. J Neurophysiol 79: 1653-1660. [Crossref]

13. Schütz B, Schäfer MK, Gördes M, Eiden LE, Weihe E (2015) Satb2-independent acquisition of the cholinergic sudomotor phenotype in rodents. Cell Mol Neurobiol 35: 205-216. [Crossref]

14. Zouboulis CC (2004) Acne and sebaceous gland function. Clin Dermatol 22: 360-366. [Crossref]

15. Toyoda M, Nakamura M, Morohashi M (2002) Neuropeptides and sebaceous glands Eur J Dermatol 12: 422-427. [Crossref]

16. Tóth BI, Géczy T, Griger Z, Dózsa A, Seltmann H, Kovács L (2009) Transient receptor potential vanilloid-1 signaling as a regulator of human sebocyte biology. $J$ Invest Dermatol 129: 329-339. [Crossref]

17. Ciociola AA, Cohen LB, Kulkarni P (2014) FDA-Related Matters Committee of the American College of Gastroenterology How drugs are developed and approved by the FDA: current process and future directions. Am J Gastroenterol 109: 620-623. [Crossref]

18. Health Canada (2016) Cosmetic Ingredient Hotlist: Prohibited and Restricted Ingredients. http://www.hc-sc.gc.ca/cps-spc/cosmet-person/hot-list-critique/index-eng. php

19. Dirty Dozen' cosmetic chemicals to avoid. http://www.davidsuzuki.org/issues/health/ science/toxics/dirty-dozen-cosmetic-chemicals/

20. Guertin PA (2016) A Novel Approach for Innovative Pharmaceutical, Nutraceutical and Biocosmeceutical Products: Different Types of Combination Products and Coactivation of Natural Synergistically Acting Target-Receptors (CanSATs). British $J$ Med and Med Research 11: 1-8.

21. Guertin PA (2016) Randomized double-blind study assessing safety and efficacy of SQIN on xerosis in subjects with mobility impairment and paralysis. J Dermatol Clin Res 4:1-5.

22. Perricone NV (2012) Formulations topiques a base d'acyl glutathione. PCT application number WO 20012/12128971 A2.

Copyright: (C2016 Guertin PA. This is an open-access article distributed under the terms of the Creative Commons Attribution License, which permits unrestricted use, distribution, and reproduction in any medium, provided the original author and source are credited. 